\title{
Influence Factors of High Cemented Gangue Backfill Strength
}

\author{
Lei Chen $^{\mathrm{a}}$, Jian Zhao ${ }^{\mathrm{b}}$ and Ming Zhao ${ }^{\mathrm{c}}$ \\ Faculty of Resource and Safety Engineering, China University of Mining and Technology, Beijing, \\ Ding No.11 Xueyuan Road, Haidian District, Beijing 100083 P. R.China \\ achenlei@cumtb.edu.cn,b1210105040@qq.com, c252797905@qq.com
}

Keywords: High cemented gangue backfill; Uniaxial compressive strength; Function relation; Influence factor

Abstract: The high cemented gangue backfill (HCGB) is prepared from coal gangue, fly ash, cement and water. The effects of curing period, slurry concentration, fly ash content and cement content on the uniaxial compressive strength (UCS) of HCGB were studied by single factor and multi-level test method. The results show that: the UCS of the HCGB follows an exponential function with slurry concentration, an exponential function with curing period also, but a power function with cement content, and decreases after increasing with increasing of fly ash content.

\section{Introduction}

With "green mining" and "scientific exploration" gradually approbated by coal mining enterprises in china, filling mining is one of the trends of the future mining development [1-3]. With the development of filling mining technology, filling body stability has become important research content, directly related to the effects of filling mining and security [4], and many scholars have made a deep research on the mechanical properties of the filling body [5-7]. Recently, Yang [8,9] of China university of mining and technology (Beijing) proposed the high cemented gangue backfill (HCGB) method, and studied the ratio of HCGB materials. But there was no scholar to analyze the influence factors of the uniaxial compressive strength (UCS) of HCGB quantitatively, and they did not give the functions between the UCS of HCGB and influence factors.

HCGB slurry mass fraction is $75 \% \sim 80 \%$, with coal gangue as aggregate, cement and fly ash as cementing materials. The factors that affect the UCS of HCGB body are concentration of slurry, cement content, fly ash content and curing time. In this research, factors affecting the UCS of HCGB body are analyzed quantitatively; the functions were studied between UCS and concentration, cement content, fly ash content and curing time.

\section{Experimental Method}

Factors affecting UCS of HCGB body basically are: content of cement, content of fly ash, slurry concentration and curing time. Based on the reference literatures[5] and [7], in the experiment, cement was designed five variables: $6 \%, 7 \%, 8 \%, 9 \%$ and $10 \%$, fly ash content was designed four variables: $15 \%, 20 \%, 25 \%$ and $30 \%$, slurry concentration was designed three variables $76 \%, 78 \%$ and $80 \%$, and the curing time was design four variables: $1 \mathrm{~d}, 3 \mathrm{~d}, 7 \mathrm{~d}$ and $28 \mathrm{~d}$.

\section{Results and Discussion}

According to the test design, coal gangue, cement, fly ash and water are mixed according to the ratio in Table 1, to form 24 groups HCGB samples, and then those samples were put into metal boxes 100 $\mathrm{mm} * 100 \mathrm{~mm} * 100 \mathrm{~mm}$ to coagulate. While coagulating, block of curing environment is relative humidity above $90 \%$, and the curing temperature is $20+2{ }^{\circ} \mathrm{C}$. The UCS of specimens was tested after the data of $1 \mathrm{~d}, 3 \mathrm{~d}, 7 \mathrm{~d}$ and $28 \mathrm{~d}$. The results as shown in table 1. 
Table1 UCS of HCGB specimens

\begin{tabular}{|c|c|c|c|c|c|c|c|}
\hline \multirow{2}{*}{ group } & \multirow{2}{*}{$\begin{array}{c}\text { slurry } \\
\text { concentration } \\
1 \%\end{array}$} & \multirow{2}{*}{$\begin{array}{c}\text { cement } \\
\text { content } / \%\end{array}$} & \multirow{2}{*}{$\begin{array}{c}\text { Fly ash } \\
\text { content } / \%\end{array}$} & \multicolumn{4}{|c|}{$\mathrm{UCS} / \mathrm{MPa}$} \\
\hline & & & & $1 d$ & $3 d$ & $7 d$ & $28 d$ \\
\hline A1 & 76 & 6 & 20 & 0.12 & 0.27 & 0.69 & 1.92 \\
\hline $\mathrm{A} 2$ & 76 & 7 & 20 & 0.21 & 0.47 & 1.01 & 2.61 \\
\hline A3 & 76 & 8 & 20 & 0.28 & 0.53 & 1.45 & 3.31 \\
\hline A4 & 76 & 9 & 20 & 0.3 & 0.68 & 1.61 & 3.85 \\
\hline A5 & 76 & 10 & 15 & 0.48 & 0.92 & 1.43 & 3.81 \\
\hline A6 & 76 & 10 & 20 & 0.51 & 1.03 & 1.76 & 4.22 \\
\hline A7 & 76 & 10 & 25 & 0.45 & 0.84 & 1.56 & 3.92 \\
\hline A8 & 76 & 10 & 30 & 0.37 & 0.71 & 1.36 & 3.78 \\
\hline B1 & 78 & 6 & 20 & 0.14 & 0.32 & 0.71 & 1.99 \\
\hline B2 & 78 & 7 & 20 & 0.23 & 0.52 & 1.08 & 2.72 \\
\hline B3 & 78 & 8 & 20 & 0.31 & 0.62 & 1.51 & 3.41 \\
\hline B4 & 78 & 9 & 20 & 0.36 & 0.72 & 1.66 & 3.97 \\
\hline B5 & 78 & 10 & 15 & 0.51 & 1.02 & 1.58 & 3.88 \\
\hline B6 & 78 & 10 & 20 & 0.52 & 1.05 & 1.89 & 4.42 \\
\hline B7 & 78 & 10 & 25 & 0.51 & 1.15 & 1.63 & 3.96 \\
\hline B8 & 78 & 10 & 30 & 0.44 & 0.82 & 1.51 & 3.91 \\
\hline $\mathrm{C} 1$ & 80 & 6 & 20 & 0.15 & 0.35 & 0.74 & 2.12 \\
\hline $\mathrm{C} 2$ & 80 & 7 & 20 & 0.27 & 0.6 & 1.19 & 2.85 \\
\hline $\mathrm{C} 3$ & 80 & 8 & 20 & 0.35 & 0.69 & 1.61 & 3.55 \\
\hline $\mathrm{C} 4$ & 80 & 9 & 20 & 0.4 & 0.78 & 1.75 & 4.15 \\
\hline C5 & 80 & 10 & 15 & 0.57 & 1.1 & 1.89 & 3.98 \\
\hline C6 & 80 & 10 & 20 & 0.55 & 1.19 & 2.19 & 4.68 \\
\hline C7 & 80 & 10 & 25 & 0.55 & 1.01 & 1.74 & 4.11 \\
\hline $\mathrm{C} 8$ & 80 & 10 & 30 & 0.54 & 0.9 & 1.71 & 4.01 \\
\hline
\end{tabular}

The Influence of Curing Time. To study the effect of curing time on the UCS of HCGB specimen, the Origin was used for fitting experimental data. Fitting relationship between UCS and curing time were obtained as table2.

Table2 Relationship between UCS of HCGB and curing time

\begin{tabular}{|c|c|c|c|}
\hline $\begin{array}{c}\text { slurry } \\
\text { concentratio } \\
n \\
\end{array}$ & $76 \%$ & $78 \%$ & $80 \%$ \\
\hline $\bar{\sigma}$ & $\sigma_{\mathrm{A} 1}=2.9723-2.982 \exp (-0.0372 \mathrm{t})$ & $\sigma_{\mathrm{B} 1}=3.2138-3.19 \exp (-0.0342 \mathrm{t})$ & $\sigma_{\mathrm{c} 1}=3.6253-3.5884 \exp (-0.031 \mathrm{t})$ \\
\hline $\mathrm{R}^{2}$ & $\mathrm{R}^{2}=0.9971$ & $\mathrm{R}^{2}=0.9995$ & $R^{2}=0.9999$ \\
\hline$\sigma$ & $\sigma_{A 2}=3.6839-3.6408 \exp (-0.0436 \mathrm{t})$ & $\sigma_{\mathrm{B} 2}=3.7093-3.6535 \exp (-0.0467 t)$ & $\sigma_{c 2}=3.6796-3.5967 \exp (-0.0524)$ \\
\hline $\mathrm{R}^{2}$ & $R^{2}=0.9995$ & $\mathrm{R}^{2}=0.9998$ & $R^{2}=0.9999$ \\
\hline$\sigma$ & $\sigma_{A 3}=4.0462-4.0787 \exp (-0.0614 t)$ & $\sigma_{\mathrm{B} 3}=4.1359-4.1268 \exp (-0.0622 \mathrm{t})$ & $\sigma_{c 3}=4.2402-4.2033 \exp (-0.0647 t)$ \\
\hline$R^{2}$ & $R^{2}=0.9876$ & $R^{2}=0.99933$ & $R^{2}=0.9968$ \\
\hline$\sigma$ & $\sigma_{A 4}=4.86-4.8657 \exp (-0.0562 t)$ & $\sigma_{B 4}=5.1236-5.07 \exp (-0.053 t)$ & $\sigma_{c 4}=5.3474-5.2631 \mathrm{exp}(-0.053 \mathrm{t})$ \\
\hline $\mathrm{R}^{2}$ & $\mathrm{R}^{2}=0.9971$ & $\mathrm{R}^{2}=0.9964$ & $R^{2}=0.9997$ \\
\hline$\sigma$ & $\sigma_{A 5}=7.1027-6.7521 \exp (-0.0256 \mathrm{t})$ & $\sigma_{B 5}=5.7046-5.3479 \exp (-0.0384 t)$ & $\sigma_{c 5}=4.7107-4.402 \exp (-0.0641 \mathrm{t})$ \\
\hline$R^{2}$ & $R^{2}=0.9966$ & $R^{2}=0.9953$ & $\mathrm{R}^{2}=0.9997$ \\
\hline$\sigma$ & $\sigma_{A 6}=5.7433-5.4513 \exp (-0.04551 t)$ & $\sigma_{\mathrm{B} 6}=5.7477-5.4891 \exp (-0.0507 t)$ & $\sigma_{c 6}=5.4713-5.2585 \exp (-0.0676 \mathrm{t})$ \\
\hline $\mathrm{R}^{2}$ & $\mathrm{R}^{2}=0.999$ & $\mathrm{R}^{2}=0.9999$ & $R^{2}=0.9999$ \\
\hline$\sigma$ & $\sigma_{A 7}=5.7165-5.4822 \exp (-0.0395 t)$ & $\sigma_{\mathrm{B} 7}=5.572-5.184 \mathrm{exp}(-0.0416 \mathrm{t})$ & $\sigma_{c 7}=5.6463-5.3163 \exp (-0.0443 t)$ \\
\hline $\mathrm{R}^{2}$ & $\mathrm{R}^{2}=0.9999$ & $\mathrm{R}^{2}=0.984$ & $\mathrm{R}^{2}=0.9998$ \\
\hline$\sigma$ & $\sigma_{A 8}=6.8757-6.6906 \exp (-0.0275 t)$ & $\sigma_{B 8}=6.1731-5.9345 \exp (-0.0344 t)$ & $\sigma_{c 8}=5.4902-5.2036 \exp (0.0449 t)$ \\
\hline$R^{2}$ & $R^{2}=0.9999$ & $R^{2}=0.9999$ & $R^{2}=0.9988$ \\
\hline
\end{tabular}

That can be seen from table 2 , the correlation coefficients of 24 groups experimental data are above 0.99. This shows that the fitting effect is well. The variation of the UCS and curing time of the filling body is exponential function relation as formula (1).

$$
\sigma_{j}=a_{1}-b_{1} e^{-c_{1} t}
$$

$\sigma_{j}-\mathrm{UCS}$ of HCGB, $a_{1}, b_{1}, c_{1}$-Constant, depending on the content of cement, slurry concentration, fly ash content and other factors, $t$-Curing time. 
In order to further study the relationship between the UCS of HCGB specimen and curing time, the change rule and the exponential function curve between the UCS of the HCGB and curing time with different cement content and different fly ash content varies were found when the slurry concentration is $76 \%, 78 \%$ and $80 \%$, as show in Fig.1. It can be seen from the figures, with the increase of cement content, the exponential curve becomes steeper, shows the UCS growing faster; with increasing of slurry concentration, the exponential curve becomes steeper, shows the UCS growing faster; with the increase of fly ash content, the exponential curve first becomes steep and then slows down, shows the influence of fly ash content on UCS of the filling body is complex.

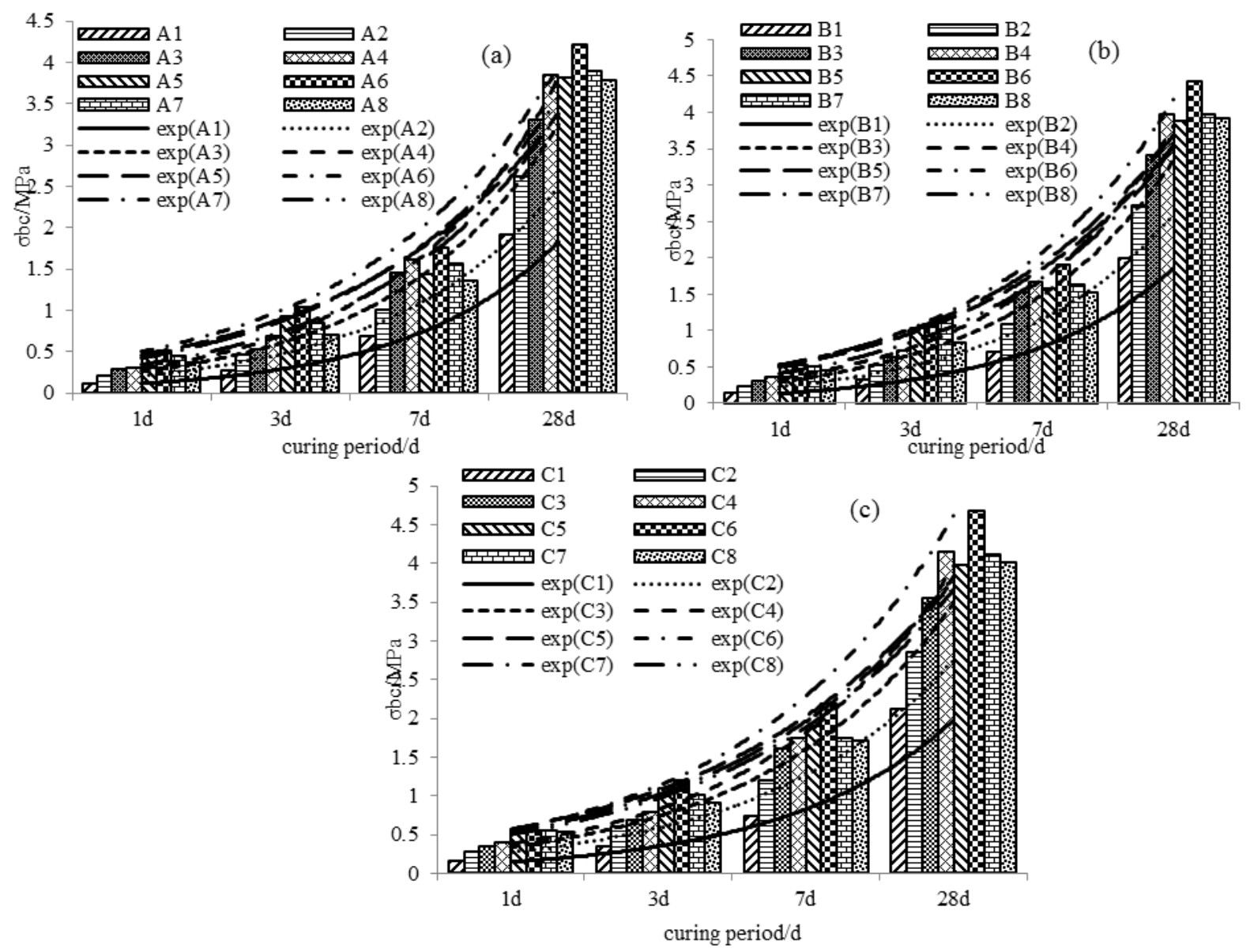

Fig.1 Relationship of curing period and the UCS of HCGB

(a) slurry concentration $76 \%$; (b) slurry concentration $78 \%$; (c) slurry concentration $80 \%$

The Effect of Cement Content. Three groups of subjects were selected, in which the content of fly ash remained unchanged at $20 \%$ and the slurry concentration were $76 \%, 78 \%$ and $80 \%$. The relationship between the UCS and cement content was studied; linear fitting and power fitting were studied; complex correlation index $\mathrm{R}^{2}$ value was obtained. The fitting results are shown in the table 3 .

Table3 Multiple correlation coefficient $\left(\mathrm{R}^{2}\right)$ of cement content and UCS

\begin{tabular}{cccccc}
\hline \multirow{2}{*}{$\begin{array}{c}\text { slurry } \\
1 \%\end{array}$} & fitting & \multicolumn{4}{c}{ curing period/d } \\
\cline { 3 - 6 } & type & 1 & 3 & 7 & 28 \\
\hline \multirow{2}{*}{$76 \%$} & linear & 0.8721 & 0.9063 & 0.937 & 0.9767 \\
& power & 0.8058 & 0.8587 & 0.9778 & 0.9995 \\
$78 \%$ & linear & 0.9565 & 0.927 & 0.9329 & 0.9871 \\
& power & 0.934 & 0.89 & 0.98 & 0.9996 \\
$80 \%$ & linear & 0.9665 & 0.8913 & 0.9704 & 0.9942 \\
& power & 0.9494 & 0.8363 & 0.97 & 0.9998 \\
\hline
\end{tabular}


It can be seen that the power fitting is better than the linear fitting from table3, so the power function is more consistent with the effect of cement content on UCS. Curves of the variation of UCS of $7 \mathrm{~d}$ and $28 \mathrm{~d}$ with the cement content under the conditions of slurry concentration $76 \%, 78 \%$ and $80 \%$ were showed in Fig.2. Along with the increase of the concentration of slurry, the slope of the curve becomes larger, which shows that the intensity increases more quickly, and the value of UCS is larger.
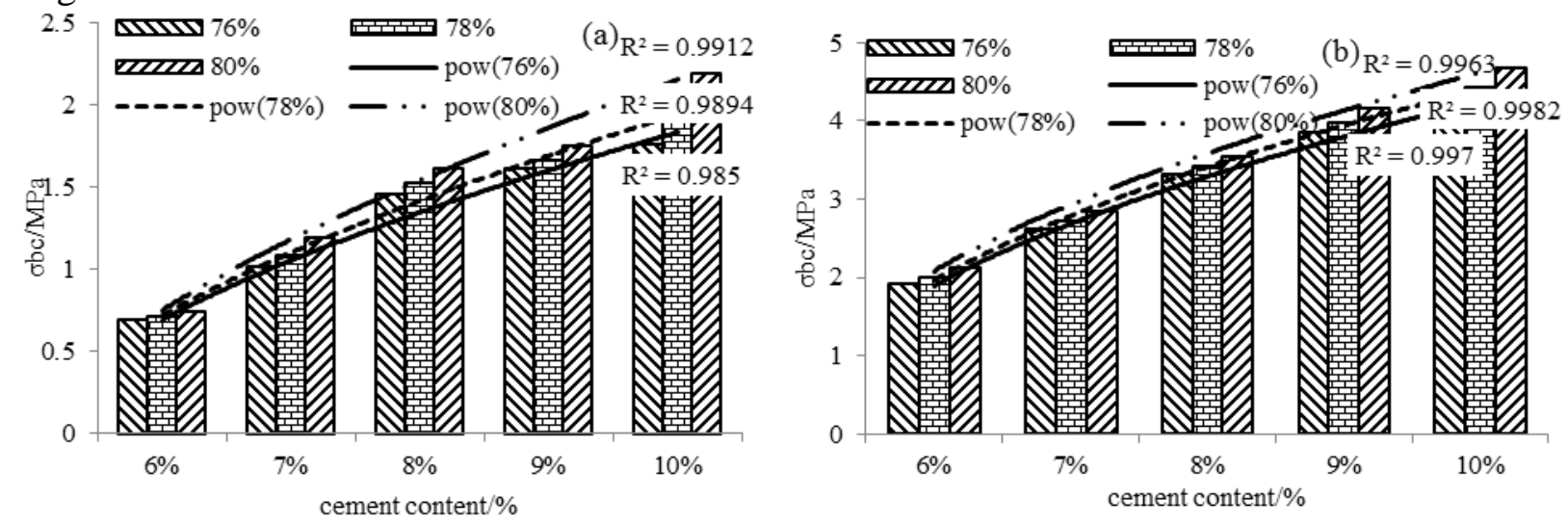

Fig.2 Relationship of cement content and UCS of HCGB (a) 7d; (b ) 28d

In summary, the relationship of the UCS of HCGB and cement content is power function. It can be expressed by formula (2).

$$
\sigma_{j}=a_{2}-b_{2} c_{2}^{x}
$$

$\sigma_{j}$ - UCS of HCGB, $a_{2}, b_{2}, c_{2}$ - Constant, depending on the content of cement, slurry concentration, fly ash content and other factors, $\mathrm{x}$-Cement content.

The Influence of Slurry Concentration. In order to study the influence of slurry concentration on the UCS of HCGB, the test data were divided into 8 groups, each of which was the same as the content of cement and fly ash. In table 1, A1, B1, C1 as a group, A2, B2, C2 as another group, and so on, totally eight groups. The relationship between the UCS and intensity of $7 \mathrm{~d}$ and $28 \mathrm{~d}$ was studied by linear fitting and exponential fitting, and the values of the complex correlation coefficient $\mathrm{R}^{2}$ were obtained, as shown in Table 4.

Table4 Multiple correlation coefficient $\left(R^{2}\right)$ of slurry concentration and UCS

\begin{tabular}{ccccccccccc}
\hline $\begin{array}{c}\text { curin } \\
\mathrm{g} \\
\text { perio } \\
\mathrm{d}\end{array}$ & $\begin{array}{c}\text { fitting } \\
\text { type }\end{array}$ & 1 & 2 & 3 & 4 & 5 & 6 & 7 & 8 & average \\
\hline \multirow{2}{*}{$7 \mathrm{~d}$} & linear & 0.986 & 0.983 & 0.979 & 0.973 & 0.961 & 0.95 & 0.983 & 0.993 & 0.9760 \\
& exp & 0.988 & 0.989 & 0.983 & 0.976 & 0.973 & 0.961 & 0.987 & 0.997 & 0.9818 \\
& linear & 1 & 0.97 & 0.997 & 0.986 & 0.989 & 0.994 & 0.942 & 0.994 & 0.9840 \\
$28 \mathrm{~d}$ & exp & 0.9999 & 0.975 & 0.998 & 0.989 & 0.99 & 0.996 & 0.945 & 0.994 & 0.9859 \\
\hline
\end{tabular}

From table 4, it can be seen that the exponential function is better than linear function with the law of the influence of slurry concentration on UCS. Fig. 3 shows the curve of the change of UCS along with the concentration of the material when the curing time is $28 \mathrm{~d}$. Diagram (a) shows the change curves of USC with concentration of slurry in the condition of different cement content and remained fly ash content $20 \%$; diagram (b) shows the change curves of UCS with concentration of slurry in the condition of different fly ash content and remained cement content $10 \%$. From the diagram (a) it can be seen, with the increase of cement content, the UCS of HCGB increased gradually; from the diagram (b) it can be seen in the fly ash content of $20 \%$, the UCS of HCGB is maximum. 

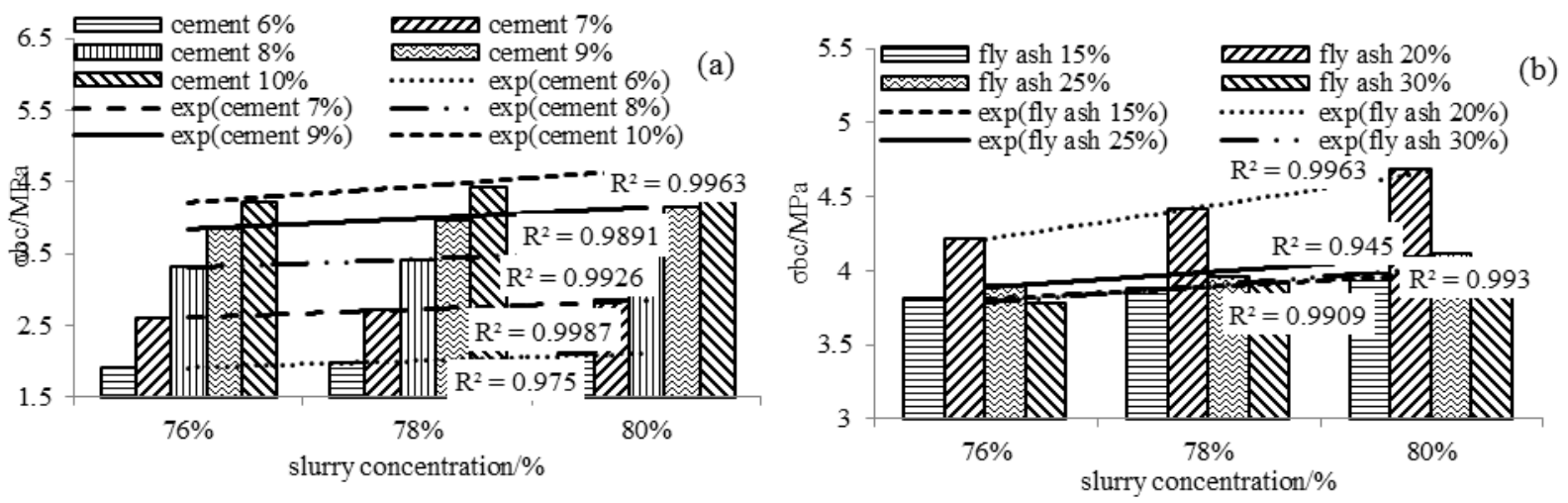

Fig.3 Relationship of slurry concentration and UCS

(a) fly ash content $20 \%$; (b) cement content $10 \%$

In summary, the effect of slurry concentration on the UCS of HCGB is exponential function. By applying the Origin for data fitting, the relation between the intensity change with slurry concentration as shown in formula (3).

$$
\sigma_{j}=a_{3}+b_{3} e^{-x / c_{3}}
$$

$\sigma_{j}-\mathrm{UCS}$ of HCGB, $a_{3}, b_{3}, c_{3}-$ Constant, depending on the content of cement, slurry concentration, fly ash content and other factors, $x$-the concentration of the slurry.

The Influence of Fly Ash Content. In order to study the influence of fly ash on the UCS of HCGB, the content of fly ash is set to $15 \%, 20 \%, 25 \%$ and $30 \%$. When the cement content is $10 \%$ and the slurry concentrations are $76 \%, 78 \%$ and $80 \%$, the relation curves between UCS and fly ash content are shown in Figure 4.

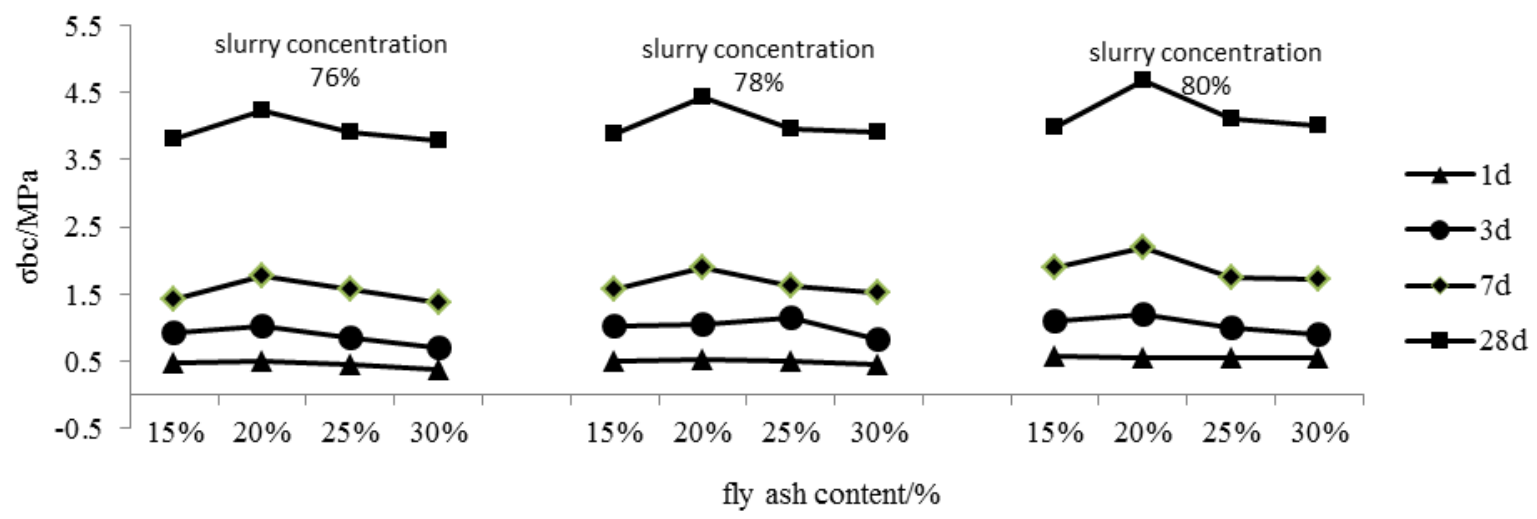

Fig.4 Relationship of fly ash content and UCS

As can be seen from Fig.4, with the increase of the content of fly ash, the UCS of HCGB increases first and then decreases, so the effect of fly ash content on UCS is more complicated. When the content of fly ash is $20 \%$, the UCS reaches the maximum value, so it can be considered that the best content of fly ash is about $20 \%$.

\section{Conclusions}

(1) The UCS of HCGB has a certain function of quantitative relationship with the content of cement, slurry concentration and curing time.

(2) The UCS of HCGB increases exponentially with the increase of curing time, of power function with the increase of cement content, and exponentially with the increase of the slurry. The maximum value of UCS is reached when the content of fly ash is $20 \%$.

(3) In order to obtain the maximum UCS, the content of fly ash of HCGB is $20 \%$, the cement content is $10 \%$, and the slurry concentration is $80 \%$.It was only considered the UCS of HCGB in this research, in fact, the rheological properties of the materials need to be further studied. 


\section{Acknowledgements}

This work was financially supported by the National Science and Technology support program of China (No.2011BAB48B02) and the Fundamental Research Funds for the Central Universities (No. 2016QZ03)..

\section{References}

[1] Zhou Aimin. Cemented filling with mining wastes [M].Beijing: Metallurgical Industry Press, 2007:50-60.

[2] Fu Jianxin, Du Cuifeng, Song Weidong. Strength sensitivity and failure mechanism of full tailings cemented backfills [J]. Journal of University of Science and Technology Beijing, 2014, 36 (9) :1149-1157.

[3] Wang X G, Tang K Y. Overview of cut and fill method for mines. Express Inf Min Ind, 2008, 12 (12):1.

[4] Zhou Baojing, Xu Jinhai, NiHaimin. The small aspect ratio backfill gob-side entry retaining stability [J].Journal of China Coal Society. 2010, 35(S) :33 37.

[5] Zhu L P, Ni W, Huang D. Whole-tailings backfilling materials with fly ash. J UnivSciTechnol Beijing, 2011, 33(10):1190.

[6] Chang Qingliang. Research on theory and practice of mining induced overlying strata deformation and surface subsidence with paste backfilling [D]. Xuzhou: China University of Mining and Technolgy, 2009:37-63.

[7] Sun Qi, Zhang Xiangdong, Yang Yu. Creep constitutive model of cemented body used in backfilling mining [J]. Journal of China coal society, 2013, 36(6):994-999.

[8] Yang Bao-gui, WANG Jun-tao, LI Yong-liang, et al. Backfill coal mining technology with high concentrated cementing material in underground mine. Coal Science and Technology, 2013, 41(8):22-26.

[9] YANG Bao-gui, HAN Yu-ming, YANF Peng-fei, et al. Research on Ratio of High Concentration Cementation Stowing Materials in Coal Mine[J]. Coal Science and Technology,2014,42(1):30-33. 